\title{
Para uma distinção entre força e violência: Benjamin e Sorel
}

\author{
VERENA SEELAENDER DA COSTA *
}

RESUMO No texto "Para a crítica da violência" (1921), Walter Benjamin refere-se diversas vezes a Georges Sorel (1847-1922), pensador francês normalmente associado ao anarco-sindicalismo e ao conservadorismo. Até que medida as reflexões sorelianas influenciaram Benjamin não é claro, porém buscaremos demonstrar que, para compreendermos o pensamento benjaminiano, é interessante antes compreender a reflexão de Sorel e, em especial, sua distinção conceitual entre força e violência. Para Benjamin e Sorel, essa distinção está fundamentalmente ligada a distinção entre greve geral política e greve geral revolucionária e à relação estabelecida entre ambas as modalidades de greve com o estatuto jurídico vigente e o direito. Porém, antes de estabelecer a relação entre a violência (ou não) da greve com o direito, é necessário definir o que significa exatamente falar na violência da greve, isto é, na greve como um ato de violência. Sorel partia da premissa de que, no capitalismo, Estado e capital estão sempre necessariamente imbricados, e que todas as formas de ação revolucionária que não busquem o fim do Estado estão fadadas a repetirem essa imbricação. A perspectiva da Estado capitalista moderno não percebe, no direito à greve, nenhum direito à violência. No entanto, a greve, quando atinge determinada intensidade - na greve geral revolucionária -, torna-se violenta do ponto de vista do Estado, que entende como sua função agora fazer uso de sua própria força para "controlar" a situação social. Para expressar a diferença entre a violência ativa da greve e a violência reativa do Estado contra a greve, Sorel cria uma distinção conceitual entre os conceitos de força e violência. Apesar de não se encontrar explicitamente nenhuma referência entre essa diferenciação no texto benjaminiano, procuraremos mostrar como a distinção soreliana lança luz sobre a distinção benjaminiana entre violência mítica e violência divina. 


\section{INTRODUÇÃO}

O texto "Para a crítica da violência” (1921) de Walter Benjamin vem sendo objeto constante de pesquisas e leituras diversas desde sua publicação. Escrito na juventude de Benjamin, esse texto, considerado um dos mais obscuros, complexos e de difícil acesso de Benjamin, serviu como inspiração mais ou menos direta para a reflexão sobre o tema na obra de variados autores e pensadores do século XX e contemporâneos, dentre eles Hannah Arendt, Giorgio Agamben, Jacques Derrida e Slavoj Zizek (Arendt, 2009; Agamben, 2004; Derrida, 2010; Zizek, 2008). O objetivo deste artigo é desenvolver, na medida do possível, a relação entre o texto de Benjamin e a coletânea de textos "Reflexões sobre a violência” (1908) do escritor francês Georges Sorel e demonstrar que a compreensão da distinção feita por Sorel entre força e violência pode ajudar a esclarecer a distinção entre violência mítica e violência divina que foi estabelecida por Benjamin no artigo sobre a violência.

Georges Sorel (1847-1922) foi um intelectual e escritor francês, conhecido principalmente pela elaboração de uma série de textos sobre a violência política e o movimento grevista, reunidos em um volume denominado "Reflexões sobre a violência" publicado em 1908 e por fundamento um viés político-ideológico que é normalmente descrito como marxista e anarco-sindicalista - apesar de ser difícil qualificar o autor como parte tanto de um movimento quanto do outro (Sorel, 1999) ${ }^{1}$. Nessas reflexões, Sorel coloca uma série de questões, propositalmente sem muita sistematicidade e numa escrita mais livre e ensaística, relacionadas à violência, à greve e ao movimento operário da época, além de discutir episódios históricos contemporâneos seus e anteriores a seu tempo. Segundo Werner Hamacher, Walter Benjamin e sua geração leu a obra de Sorel dentro do contexto dos debates estratégicos sobre o uso da greve e da expulsão do anarco-sindicalismo durante as discussões da Primeira Internacional em 1872 (Hamacher, 1991; Cantinho, 2012).

1 C. Salzani, em seu artigo sobre Benjamin e Sorel, descreve como as "Reflexões sobre a violência" foram posteriormente atribuídas ao pensamento fascista ou pré-fascista, especialmente porque foram elegidos por figuras como Mussolini como leituras de importância (Salzani, 2008). 
No entanto, é perceptível que, apesar de Sorel estar longe de ser uma das principais referências de Benjamin no geral, ainda assim existem muitos reflexos de seus textos na formulação do texto de Benjamin para além da dicotomia entre os tipos de greve, a qual ele remete explicitamente a Sorel (Benjamin, 2013). O reflexo mais perceptível diz respeito à terminologia utilizada pelo autor alemão, que é bastante coincidente com a de Sorel: conceitos como o de greve geral proletária e greve geral política, de violência revolucionária, de mito etc. Isso não significa que Benjamin utilize os mesmos conceitos que Sorel, mas sim que há um parentesco, mesmo que distante e muitas vezes puramente nominal, entre as ideias deste e daquele. Isso se torna especialmente interessante porque ajuda a compreender o pensamento de Benjamin, já que seu texto, apesar de muito rico em ideias e conceitos, é extremamente curto.

\section{A GREVE E A VIOLÊNCIA (BENJAMIN)}

O artigo "Para a crítica da violência” [Zur Kritik der Gewalt], publicado em 1921 na revista "Archiv für Sozialwissenschaft und Sozialpolitik", tem como objetivo anunciado em suas primeiras linhas, uma avaliação crítica $^{2}$ do conceito de violência como meio, independentemente de seus fins. Esse debate será estabelecido por ele através de um diálogo com as teorias sobre a greve enquanto ato de violência - ou não. Nele, Benjamin afirma que a greve é entendida, por um lado, como uma ação realizada pelos trabalhadores, dentro do contexto maior da luta de classes, que coletivamente decidem suspender o exercício da atividade laboral com o fim de obter melhorias tanto no ambiente de trabalho como nas suas condições de vida em geral. Porém, por outro lado, a greve é um direito reconhecido da classe trabalhadora pela autoridade jurídica moderna. Essa duas faces da greve representam duas perspectivas, já que a greve se dá dentro do domínio da luta de classes, em que necessariamente se parte de dois pontos de vista opostos. A perspectiva da Estado burguês não vê, no direito à greve, nenhum direito à violência. A greve consiste em um “alheamento” dos empregados em relação

2 Como Derrida e Cantinho chamam a atenção, a palavra "crítica", aqui, tem um sentido kantiano, em oposição àquele normalmente associado ao senso comum - principalmente a acepção negativa da palavra. Nesse caso, uma crítica é uma exposição de um determinado assunto, de forma que alguma luz seja jogada sobre os erros que normalmente são cometidos na sua exposição. O problema não está na violência enquanto conceito isolado; da mesma maneira que Kant rejeita um saber sobre a natureza das coisas, o que está em jogo aqui não é a natureza da violência, mas sim os problemas que as análises existentes apresentam ao tentar estabelecer um saber sobre a violência enquanto objeto (Derrida, 2010; Cantinho, 2012; Kant, 2001). 
ao patrão, uma forma de se subtrair à violência que o patrão lhes inflige indiretamente: o ato da greve é visto como um ato de subtração, de se afastar do trabalho em razão de uma violência. A perspectiva proletária, no entanto, não é a mesma. Do ponto de vista dos trabalhadores, o direito à greve é um direito ao uso da violência para que se alcancem determinados fins.

Essa contradição entre o ponto de vista do Estado e o ponto de vista dos trabalhadores alcança sua maior visibilidade diante de uma situação específica, segundo Benjamin. É a que ele chama de "greve geral proletária" - nome é citado por ele em referência à teoria de violência revolucionária de Georges Sorel (Benjamin, 2013, p. 129). A greve geral revolucionária é aquela que é verdadeiramente e necessariamente violenta do ponto de vista do proletariado. Porém, como foi afirmado anteriormente, o Estado, para aceitar a legalidade da greve, deve observá-la como um agir não-violento. Por isso, o que se observa é que o direito à greve no Estado burguês só é válido até certo ponto. A partir de certa medida, o uso da não-violência da greve (do ponto de vista do Estado) se torna uma espécie de "abuso", afinal, o direito à greve não foi concedido para ser usado dessa forma. A greve, quando atinge determinada intensidade, torna-se violenta do ponto de vista do Estado, que vê como sua função agora fazer uso de sua própria força para “controlar” a situação social.

A princípio, se o direito à greve é uma garantia do estado democrático burguês por ser reconhecido como uma "não-violência" reativa à violência dos donos dos meios de produção; entretanto, no momento em que todas as empresas entram em greve simultaneamente é declarada a ilegalidade da greve geral revolucionária. A passagem do supostamente pacífico direito à greve que o Estado garante à declaração da ilegalidade da greve não é problemática para o direito. Como foi afirmado anteriormente, a justificativa do perigo à coesão e à ordem social é somente uma parte da explicação para a limitação da vigência do direito à greve. O motivo pelo qual o Estado, baseado nas premissas jurídicas, não permite a greve geral é que a violência da greve geral, mais do que ameaçar a ordem social, ameaça o próprio estatuto jurídico-político que a mantém (Benjamin, 2013).

Essa verdade se deixa perceber de forma explícita no caso da greve geral revolucionária na intensidade da violência que o próprio Estado faz uso para impedir a violência da greve ilegal. Nas palavras de Benjamin: “Nesta [na greve geral revolucionária], a 
classe trabalhadora invocará sempre seu direito à greve, mas o Estado chamará este apelo de abuso (pois o direito à greve não foi pensado 'desta maneira') e promulgará seus decretos de emergência" (Benjamin, 2013: 129). Os decretos de emergência são uma suspensão das leis que a própria lei permite. Como afirma Benjamin, o fato da greve ser às vezes legal e às vezes ilegal não é uma contradição na teoria do direito, mas sim de ordem prática: "Evidencia-se uma contradição apenas na situação de direito, mas não uma contradição lógica no direito, quando, sob determinadas condições, o direito reage aos grevistas, enquanto praticantes da violência, com violência” (Benjamin, 2013: 129).

Nesse ponto, Benjamin traz uma nova adjetivação ao conceito de violência a partir dos fins. A violência que ele denomina predatória seria uma violência cujo fim seria apenas se apoderar de algo - como, por exemplo, em uma guerra, na qual o objetivo é se apropriar de determinado território (Benjamin, 2013). Nesse sentido, essa violência se mostraria incapaz de modificar estruturas sedimentadas e, muito menos, de criar novas estruturas sociais. A violência da greve, por ter objetivos práticos, poderia ser, dessa maneira, classificada de predatória, já que visa se apropriar de fins sem necessariamente trazer mudanças estruturais. Porém, Benjamin alerta que, se a violência da greve fosse simplesmente predatória, o Estado não reagiria com tanta violência em relação a ela. Na verdade, o que o Estado teme na violência da greve não é tanto sua função predatória, mas sim outra coisa. A greve deixa clara esta outra função da violência: a capacidade de modificar e, especialmente, criar novas relações de direito. Nas palavras do autor: “A greve, porém, mostra que a violência consegue isso, que é capaz de fundamentar e modificar as relações de direito, por mais que o sentimento de justiça possa se sentir ofendido com isso." (Benjamin, 2013: 130).

A violência com que o Estado reage à violência de classe - cuja manifestação é a greve - está relacionada ao mesmo medo do Estado de ter suas relações político-jurídicas modificadas. Por isso o direito à greve só é concedido na medida em que o caráter potencialmente violento - isto é, potencialmente capaz de modificar relações jurídico-políticas - da greve não ficar evidente. No entanto, tanto no caso da guerra estatal quanto no da guerra entre classes, o Estado é muitas vezes obrigado a reconhecer essa violência e legitimar o direito que dela é originado. 


\section{VIOLÊNCIA CONSERVADORA E VIOLÊNCIA INSTAURADORA}

A partir do momento em que são delimitadas claramente estas duas funções da violência - ou seja, a violência tem, dependendo da situação, tanto a função de manter uma determinada ordem jurídica quanto a de modificar essa ordem - é que se pode iniciar, na concepção de Benjamin, uma crítica da violência enquanto meio (Benjamin, 2013). De fato, essas duas funções estão essencialmente ligadas: a violência da manutenção do direito é justificada em nome da reação à outra violência que ameaça mudar essa ordem. Essas funções, no entanto, não são exatamente contraditórias: às vezes uma violência se reveste de determinado tipo de função para, no momento seguinte, revestir-se da outra, e há casos em que as duas são exercidas ao mesmo tempo. O direito da guerra expõe de forma bastante clara os usos da violência e sua relação com o direito: quando o vencedor se apossa do território inimigo por meio da violência militar, ele precisa determinar um novo direito para estabilizar a situação político-jurídica e, com com essa estabilização, poder fazer uso da violência para reprimir novas violências que ameacem essa nova ordem recém-estabelecida.

Esse impasse do direito é também de onde se deriva o direito à greve. O Estado concedeu tal direito para evitar a violência que os operários utilizavam para fazer reivindicações, já que esta obrigava o Estado a recorrer a manifestações brutais de violência. Por isso para Benjamin a greve é um meio puro. O Estado moderno transformou a violência da greve em um tipo de violência com o qual está muito mais habituado: a violência do contrato jurídico. Todo contrato remete à violência estatal, pois é da autoridade estatal que ele deriva sua força. Benjamin chama a atenção para como o contrato, ou seja, o compromisso, tornou-se na Modernidade quase a única forma de tratar de problemas políticos - sejam eles quais forem. Isso ocorreu justamente porque os próprios Parlamentos (espaços por definição para tratar de problemas políticos) se esqueceram da violência não-jurídica de suas origens e substituíram a atividade política pela atividade do compromisso e do firmamento de contratos (Benjamin, 2013; Avelar, 2009).

De fato, o direito na visão de Benjamin sofre de um abalo em decorrência do esquecimento de suas origens (Benjamin, 2013). O direito evita manifestações explícitas e brutais de violência, ou seja, manifestações que causem desconfiança e remetam à sua origem violenta. Para evitar ter que recorrer ao uso da violência brutal - já que 
esta explicitaria o próprio fundamento do estatuto jurídico - o direito cria fins para si próprio de maneira em que a violência da mentira, por exemplo, seja transformada na violência do contrato. O mais importante é notar que estas duas violências são muito diferentes. elas são essencialmente diversas: enquanto todo contrato remete a uma violência estatal e deriva de um poder superior; a violência da linguagem é, em sua essência, não-violenta. Isso se dá porque o meio da linguagem é um meio puro, ou seja, um meio no qual a violência está essencialmente excluída.

\section{GReVe geral proletária e greVe geral política (SOREL)}

Porém, antes de detalhar a relação entre violência da greve e Estado, Benjamin destaca que existem duas modalidades totalmente distintas de greve geral que devem ser diferenciadas. Estas modalidades, que ele toma de empréstimo de Georges Sorel, são as da greve geral proletária e greve geral política (Benjamin, 2013: 141). Como foi mencionado anteriormente, a greve geral proletária consiste em uma greve cujo objetivo não é puramente uma melhora nas condições de trabalho. A greve geral proletária é uma greve que busca solapar de forma absoluta o sistema político e o estatuto jurídico do qual esse sistema deriva a sua autoridade. A greve geral política, por outro lado, não tem objetivos tão amplos. Em geral, ela busca fazer pequenos compromissos políticos entre patrões, legisladores e empregados. A lógica empregada por ela é a mesma lógica do parlamentarismo, ou seja, firmar contratos reconhecidos pela autoridade político-jurídica e derivar desses contratos a sua força. Nela, não há qualquer tipo de pretensão à mudanças de fato estruturais na organização social. Seu objetivo é puramente circunstancial e material, e ela normalmente é motivada por razões econômicas (Sorel, 1999). Nas palavras de Sorel, citado por Benjamin:

A base de suas concepções é o fortalecimento do poder do Estado [Staatsgewalt]; em suas organizações atuais, os políticos (a saber, os socialistas moderados) preparam desde já a instituição de um poder forte, centralizado e disciplinado, que não se deixará perturbar pela crítica da oposição, saberá impor o silêncio e baixar seus decretos mentirosos. (...) A greve geral política (...) demonstra como o Estado não perderá nada de sua força [Kraft], como o poder [Macht] passa de privilegiados para privilegiados, como a massa dos produtores mudará de dono. (Sorel apud Benjamin, 2013: 141-142)

A greve geral revolucionária, por outro lado, é exatamente o oposto desta modalidade. Nela não são buscados compromissos ou contratos. Ela não estabelece qual- 
quer relação com o direito e nem deriva nenhuma força dele; pelo contrário, a única relação que a greve geral proletária tem com estas instituições é de total oposição e confronto. Ao contrário da greve política, ela não é reformista e sim essencialmente revolucionária: o objetivo dos trabalhadores, nesse caso, não é retornar imediatamente ao trabalho após algumas concessões materiais ou mudanças externas às condições de trabalho (como salários, férias etc), mas sim em retornar apenas quando as condições de trabalho sofrerem uma mudança interior e estrutural. Esse tipo de mudança realmente material nas condições de trabalho significa o fim do trabalho explorador e, em consequência disso, o fim da sociedade burguesa. Uma mudança legislativa no regime, como é o caso da greve política, não tem a potência para realizar isso por si só, pois o Estado não concede à greve tal potência de transformação no pensamento de Sorel (Sorel, 1999). Nas palavras de Benjamin:

Em oposição a essa greve geral politica (cuja fórmula, diga-se de passagem, parece ser a da passada revolução alemã [revolução alemã de 1918]), a greve geral proletária se propõe, como única tarefa, aniquilar o poder do Estado. Ela 'exclui todas as consequências ideológicas de qualquer política social possível; seus partidários consideram até mesmo as reformas mais populares como burguesas.' [citação do Sorel] Essa greve geral proclama muito claramente sua indiferença quanto ao ganho material da conquista, ao declarar que quer abolir o Estado; o Estado era de fato a razão de ser dos grupos dominantes, que tiram proveito de todos os empreendimentos cuja carga recai sob o conjunto da população. (Benjamin, 2013: 142-143)

Para Sorel, a greve geral revolucionária, ao contrário da greve política, não deve se caracterizar como uma mera mudança de donos do poder, mas sim algo que é capaz de modificar completamente as estruturas de poder da sociedade (Sorel, 1999). Por exemplo, Sorel não considerava a Revolução Francesa como uma revolução de fato, pois o que ele observava era uma mudança de elites (da aristocracia para a burguesia) que não teve reflexos materiais na forma como o trabalho na sociedade francesa se organizava. Em sua visão, uma troca de minoria governante não é o bastante para modificar, de fato, a estrutura social. Essa mudança somente poderia vir a partir de uma autêntica revolução social, ou seja, na forma de uma greve geral proletária capaz de eliminar, em um só golpe, a estrutura hierárquica da sociedade e criar uma sociedade nova, sem classes nem hierarquias.

Para Sorel, um dos grandes problemas da teoria marxista é uma ausência de diferença entre o nome da violência utilizada pelo Estado contra as classes despossuídas e o 
nome da violência dessas mesmas classes em reação ao Estado e às relações capitalistas. O autor francês partia da premissa de que, no capitalismo, Estado e capital estão sempre necessariamente imbricados, e que todas as formas de ação revolucionária que não busquem o fim do Estado estão fadadas a repetirem essa imbricação. Dessa maneira, a ação do Estado de conter as forças proletárias deve ser chamada de "força”, enquanto somente as ações do proletariado devem ser propriamente chamadas de "violência".

\section{FORÇA E VIOLÊNCIA, VIOLÊNCIA MÍTICA E DIVINA - CONCLUSÃo}

O que se observa é que a violência de que Sorel fala é uma violência destituída de força - que deve ser entendida como a força de uma minoria opressora sobre uma maioria oprimida. A violência revolucionária é, por mais estranho que pareça, uma violência sem força, que não toma empréstimo dela, nem de nenhum direito, tampouco faz dela uso para destruir inimigos. Como observa Jennings, o que Sorel chama de violência é algo que nada tem de violento, e que se resume a pouco mais do que gestos heroicos do proletariado (Sorel, 1999). O texto de Benjamin não deixa claro se este concorda ou não com esta definição de violência, mas percebe-se que há uma forte influência de Sorel na formulação de Benjamin. Porém, Benjamin claramente pensava que a greve proletária, por não buscar concessões nem compromissos, ou seja, por não se submeter ao esquema de meios e fins presente no contrato jurídico, era um meio puro. Como foi explicado, meios puros são essencialmente destituídos de violência “violência”, nesta frase, deve ser entendida como o conceito de “força” de Sorel -; ou seja, enquanto a greve política é uma greve violenta, pois baseia sua força na força do contrato, a greve proletária é, nas palavras de Benjamin, "não-violenta": "Enquanto a primeira forma de suspensão do trabalho [na greve geral política] é violenta, uma vez que provoca só uma modificação exterior nas condições de trabalho, a segunda [greve geral proletária] enquanto meio puro, é não-violenta.” (Benjamin, 2013: 143).

A greve geral proletária demonstra seu caráter de meio puro por não ter fins nem justos nem injustos. Para Benjamin, enquanto a greve geral política é, em sua essência, instauradora do direito, a greve geral proletária é, analogamente, destituidora do direito; ela é, na expressão dele, anarquista: “Na esteira de algumas observações de Marx, Sorel recusa para o movimento revolucionário qualquer tipo de programas, utopias, numa palavra, de instaurações de quaisquer formas de direito.” (Benjamin, 
2013: 143-144)33. A greve geral proletária é um tipo de subversão que ela mesma desencadeia e leva à completude (Benjamin, 2013). O caráter não-violento deste tipo de greve não significa que uma situação revolucionária não possa resultar em violência, mas aqui se aplica, na visão de Benjamin, a "lei dos meios": julgar um meio a partir de seus efeitos, ou seja, a partir de seus fins, não é julgar o próprio meio, mas sim os efeitos. Como o Estado só consegue julgar as coisas a partir de seus fins (como foi explicado anteriormente, o direito, por se basear no esquema de meios e fins, é incapaz de observar meios puros ou de até mesmo admitir a sua existência), a greve geral proletária nunca será para ele um meio puro, mas sim uma violência, uma situação de descontrole social.

Benjamin também pensa em uma violência que não engendra um direito ao se manifestar. A modalidade de violência que ele chama de divina é a única violência verdadeiramente pura do ponto de vista dos meios, pois ela não mantém relações com o direito. Ela rompe o ciclo eterno de culpa e expiação promovido pela violência mítica - e é essa a dicotomia sobre a qual o texto benjaminiano se apoia. O movimento cíclico da violência mítica se manifesta de duas formas: a forma da violência fundadora do direito e a forma da violência mantenedora do direito. Porém, como foi visto, essas formas não são claramente discerníveis; é justamente sua ambiguidade que sustenta sua indeterminação. Essa alternância se dá da seguinte forma: há uma violência constituinte, que funda um direito e se estabelece como soberano; no entanto, outros direitos concorrem com ela e tentam substituí-la; para reagir a essas novas violências, o direito se utiliza da violência que mantém a ordem do direito; eventualmente, uma nova violência se sobrepõem à antiga e uma nova ordem do direito é fundada por ela, iniciando novamente o ciclo. Na terminologia proposta por Georges Sorel, esse movimento indicaria somente uma alternância de poder por meio do uso da força (isto é, a ação das classes dominantes sobre as dominadas, ou de uma minoria sobre a maioria). A violência divina, que é a que Sorel diz ser a única violência digna desse nome, é uma interrupção desse ciclo, e é descrita por Benjamin da seguinte forma:

É na ruptura desse círculo atado magicamente nas formas míticas do direito, na destituição do direito e de todas as violências das quais ele depende, e que de-

3 Benjamin ao escrever esse trecho tinha em mente uma carta escrita em 1896 para o historiador inglês Edward Spencer Beesly na qual Marx afirmava que a atividade de traçar programas futuros para o proletariado é reacionária (Hamacher, 1991). 
pendem dele, em última instância, então, na destituição da violência do Estado, que se funda uma nova era histórica (Benjamin, 2013: 155)

Violência mítica e violência divina são, então, antitéticas não apenas por apresentarem modalidades diversas de um mesmo movimento - como, por exemplo, no caso da violência instauradora (ou fundadora) de um direito e na mantenedora (ou conservadora) desse direito - mas pela violência de caráter divino ser a superação e extrapolação desse ciclo. A violência mítica, na perspectiva de Benjamin, é sangrenta, ou seja, tem um parentesco com a ordem sacrificial presente na estrutura dos mitos e que, por um processo complexo, abastardou-se no direito moderno através de uma deformação e secularização ao longo do tempo (Adorno, Horkheimer, 1985). A violência divina, por outro lado, é desestruturadora; seus sacrifícios não só não buscam reforçar o ciclo de expiação característico do sacrifício mítico, mas tem como razão estancar o sangramento expiatório e deixar a vida seguir seu fluxo, sem com isso estabelecer uma nova ordem hierárquica - e, a partir dela, a necessidade de novos sacrifícios. A violência mítica apenas pode basear sua existência no uso da força do forte contra o fraco e, por isso, é essencialmente injusta. A violência divina é a violência do fraco contra o forte e, assim, sempre será necessariamente não-violenta; nas palavras de Benjamin, ela é a única que pode ser legitimamente chamada de "violência reinante" [waltende Gewalt $]^{4}$.

4 A tradução utilizada aqui para a expressão alemã "waltende Gewalt” é a de Ernani Chaves, tradutor do texto na edição brasileira (Benjamin, 2013). No entanto, no original há um jogo de palavras intraduzível entre as palavras "waltende" e "Gewalt", e que se sustenta no fato do substantivo "Gewalt" e o verbo "walten" (de onde deriva o particípio "waltende”) se referir tanto à violência em seu sentido mais estreito quanto ao poder estatal/jurídico de um Estado. 


\section{REFERÊNCIAS BIBLIOGRÁFICAS}

ADORNO, T., HORKHEIMER, M. Dialética do Esclarecimento: Fragmentos filosóficos. Rio de Janeiro: Jorge Zahar, 1985.

AGAMBEN, G. Estado de Exceção. São Paulo: Boitempo, 2004.

ARENDT, H. Sobre a violência. Rio de Janeiro: Civilização Brasileira, 2009.

AVELAR, I. O pensamento da violência em Walter Benjamin e Jacques Derrida. Cadernos Benjaminianos. Belo Horizonte, n. 1, 2009, pp. 1-18. Disponível em http://www.idelberavelar.com/cadernos-benjaminianos.pdf, acesso em 10/06/17.

BENJAMIN, W. Escritos sobre mito e linguagem. São Paulo: Duas Cidades; Editora 34, 2013.

CANTINHO, M. Violência divina e violência messiânica em Walter Benjamin. Cadernos Benjaminianos. Belo Horizonte, n. 5, 2012, pp. 33-43. Disponível em http://www.periodicos.letras.ufmg.br/index.php/cadernosbenjaminianos/article/view/5343/4751, acesso em $10 / 06 / 17$.

DERRIDA, J. Força de lei: o fundamento místico da autoridade. São Paulo: Editora WMF Martins Fontes, 2010.

HAMACHER. W. Afformative, Strike. Cardozo Law Review. Vol. 13, Dez. 1991, n. 4, pp. $1133-1157$.

SALZANI, C. Violence as Pure Praxis: Benjamin and Sorel on Strike, Myth and Ethics. COLLOQUY text theory critique. Vol. 16, 2008, pp. 18-48.

SOREL, G. Reflections on Violence. Melbourne: Cambridge University Press, 1999.

ZIZEK, S. Violência. São Paulo: Boitempo Editorial, 2008. 